\title{
Characterization of Compactness of Rust Layers on Weathering Steels by an Adsorption/Dehydration Test of Ethanol
}

\author{
Lujun Zhou ${ }^{1}$. Shanwu Yang ${ }^{1}$ - Yi Dong ${ }^{1}$ - Wenhua Zhang ${ }^{1}$ Jianwen Ding ${ }^{1} \cdot$ Guoliang Liu ${ }^{1} \cdot$ Chengjia Shang $^{1}$. \\ Raja Devesh Kumar Misra²
}

Received: 27 August 2019/ Revised: 11 November 2019 / Published online: 6 February 2020

(C) The Chinese Society for Metals (CSM) and Springer-Verlag GmbH Germany, part of Springer Nature 2020

\begin{abstract}
A new method for evaluating the compactness of rust layers on steels has been proposed in the present study. The method includes adsorption and dehydration process of anhydrous ethanol. The protective ability of rust layers can be qualitatively reflected by the adsorption/dehydration rates. The specific surface area and porosity of rust layers can be calculated by a quantitative model. The results from the present method are consistent with electrochemical tests, $\mathrm{N}_{2}$ adsorption and X-ray diffraction analysis. The method characterizes the compactness of rust layers rather than that of corrosion products removed from the metal surfaces, which is generally practiced in classic $\mathrm{N}_{2}$ adsorption method. Furthermore, the method can reflect the compactness of inner rust layers, to which $\mathrm{N}_{2}$ adsorption is unavailable. The method provides a new approach for the study of rust layers.
\end{abstract}

Keywords Weathering steel $\cdot$ Rust layers $\cdot$ Ethanol adsorption/dehydration $\cdot$ Specific surface area

\section{Introduction}

The structures and properties of rust layers are crucial to corrosion of steels. The compact rust layers on weathering steels [1] act as protective layer against further corrosion by inhibiting diffusion of ions and molecules, providing high atmospheric corrosion resistance [2, 3]. The compactness of rust layers or pores in the layers is determined by the morphology of rust particles such as particle size and shape. The particle size of rusts is usually estimated by powder X-ray diffraction (XRD) [4], infrared spectroscopy (IR) [5] and Mossbauer spectroscopy, while the shape of fine particles is observed by electron microscopy. The rust resistance obtained by electrochemical impedance spectroscopy (EIS)

Available online at http://link.springer.com/journal/40195.

Shanwu Yang

yangsw@mater.ustb.edu.cn

1 Collaborative Innovation Center of Steel Technology, University of Science and Technology Beijing, Beijing 100083, China

2 Department of Metallurgical, Materials and Biomedical Engineering, University of Texas at El Paso, El Paso, TX 79968, USA
[6] reflects the ability of rust layer to resist the attack from the corrosive media $[7,8]$ and therefore can be used as a major index for evaluating the protective ability of rust layers $[9,10]$. The methods above are commonly used for structural characterization of rust layers $[11,12]$ and acquisition of the structure-performance relationship [2,13].

In general, the compactness of rust layers is directly related to the presence of pores in the rust layers, which determine the permeability of $\mathrm{O}_{2}, \mathrm{H}_{2} \mathrm{O}$ and $\mathrm{Cl}^{-}$through the rust layer during the corrosion process. For this reason, specific surface area analysis is necessary. Currently, the gas adsorption method $\left(\mathrm{N}_{2}\right.$ adsorption method [14] most commonly used) is unique to characterize the pores in the rust layer and is listed as a standard test for specific surface area of rust layers in ISO 9277-2010 [15] and GB/T 195872004 [16]. The $\mathrm{N}_{2}$ adsorption method can be used to analyze micropores and mesopores, which are thought to govern the diffusion of molecules and ions in the rust layers.

The studies on texture of rusts on weathering steels containing $\mathrm{Cu}$ by $\mathrm{N}_{2}$ adsorption have been carried out by Hisamatu et al. [17, 18]. It was found that the specific surface area increased with the increase of copper content. The $\mathrm{N}_{2}$ adsorption test was also introduced by Ishikawa et al. to estimate the compactness of rust layers formed by exposure or cyclic corrosion test (CCT) of different kinds of weathering 
steels [19-23] and binary alloys of $\mathrm{Fe}-\mathrm{Cr}, \mathrm{Fe}-\mathrm{Ni}$ and $\mathrm{Fe}-\mathrm{Cu}$ [24] in different environments. It has been successfully demonstrated that the specific surface area measurement is a quantitative technique for appraisal of the protective function of rust layers. However, in $\mathrm{N}_{2}$ adsorption method, the corrosion products need to be scraped off and the integrity of rust layers is destroyed. On the other hand, the method is difficult to analyze the inner rust layer from which resistance to atmospheric corrosion mainly originates, because the inner rust layer is very thin and closely adheres to the steel matrix. Additionally, there are many factors affecting the test, such as the degassing temperature of sample and degassing time [25].

The adsorption of $\mathrm{N}_{2}$ and $\mathrm{H}_{2} \mathrm{O}$ was investigated by Ishikawa et al. [20]. It was found that the rust layers formed in the environment with high $\mathrm{NaCl}$ content adsorbed $\mathrm{H}_{2} \mathrm{O}$ more than $\mathrm{N}_{2}$ because of $\beta-\mathrm{FeOOH}$ crystals formed in the presence of $\mathrm{Cl}^{-}$. Considering the role of moisture in the corrosion resistance of rust layers, water adsorption method was further developed by Zhang et al. [26, 27], Zhang et al. [28] and Han et al. [29], based on weight loss/gain test [30-32]. Compared to $\mathrm{N}_{2}$ adsorption, the method could avoid artificial damage to the rust layers, but the problem is that it may cause further corrosion.

In the present study, an ethanol adsorption/dehydration method has been proposed to estimate the compactness of rust layers on weathering steels. The method will be used to reflect a static property of rust layers. The results from the new approach are compared with those of $\mathrm{N}_{2}$ adsorption, $\mathrm{X}$-ray diffraction and electrochemical tests, to verify the reliability of new method.

\section{Materials and methods}

\subsection{Specimen Preparation}

Three types of weathering steels, namely low-carbon bainitic steel (LCB steel), E550 steel and Corten-A steel, were employed in the present investigation. The chemical compositions of the steels are listed in Table 1.

The steels were cut into three different sizes for wet-dry cyclic corrosion test. Rectangular samples of $40 \mathrm{~mm} \times 40 \mathrm{~mm} \times 4 \mathrm{~mm}$ were used to evaluate the adsorption and dehydration capability. The rust powder for X-ray diffraction (XRD) and $\mathrm{N}_{2}$ adsorption test was also collected from the rusted samples of $40 \mathrm{~mm} \times 40 \mathrm{~mm} \times 4 \mathrm{~mm}$. Samples of $20 \mathrm{~mm} \times 10 \mathrm{~mm} \times 4 \mathrm{~mm}$ were used for rust layer analysis by scanning electron microscopy (SEM). For electrochemical measurements, samples of $10 \mathrm{~mm} \times 10 \mathrm{~mm} \times 4 \mathrm{~mm}$ were used, and the wires for electrical connections were soldered to the samples. All the samples were embedded in epoxy resin, and only the largest surfaces were exposed for corrosion test. The exposed surface of each sample was mechanically ground with 600 grit $\mathrm{SiC}$ papers.

\subsection{Wet-Dry Cyclic Corrosion Tests}

Indoor accelerated corrosion methods, as described in the literature [26], were used to simulate the atmospheric corrosion process, in order to increase the efficiency and to facilitate the selection and control of environmental parameters, which are beneficial for reproducibility and comparability of the experimental results. The specific steps were as follows: $0.5 \% \mathrm{NaCl}$ (mass fraction) aqueous solution was added to the samples horizontally placed each $12 \mathrm{~h}$. The amount of added solution depends on the surface area of the samples according to $0.04 \mathrm{~mL} / \mathrm{cm}^{2}$. The samples were washed with deionized water to prevent the accumulation of progressive salt before each test. An environment of $25^{\circ} \mathrm{C}$ and $60 \% \mathrm{RH}$ was maintained by a humidifier.

\subsection{Electrochemical Tests}

Electrochemical workstation VersaSTAT4 was used. The electrochemical device consisted of a three-electrode system, with platinum as the counter electrode, saturated calomel electrode (SCE) as the reference electrode and the tested samples as the working electrode. The electrochemical impedance spectra (EIS) measurement was carried out at room temperature in $0.5 \% \mathrm{NaCl}$ (mass fraction) aqueous solution with an amplitude of $10 \mathrm{mV}$ and a frequency range of $10^{-2}-10^{5} \mathrm{~Hz}$. The polarization curves were obtained by Tafel method with a scanning range of $0.5 \mathrm{~V}$ and a scanning rate of $10 \mathrm{mV} / \mathrm{min}$. The data were taken after measuring the open-circuit potential for $1800 \mathrm{~s}$, and the change rate of open circuit potential was less than $0.1 \mathrm{mV} / \mathrm{s}$.

\subsection{Rust Layer Analysis}

X-ray diffraction (XRD) analysis was carried out in a TTRIII multifunctional XRD instrument using a $\mathrm{Cu}$ target at a scan speed of $2 \%$ min and $2 \theta$ rang of $10^{\circ}-55^{\circ}$ in which characteristic peaks of each phase involved in the rust layers are present. The quantitative analysis of rust was conducted with $\mathrm{ZnO}$ as an internal standard matter. The mass ratio
Table 1 Chemical compositions of weathering steels (mass\%)

\begin{tabular}{lcccccccc}
\hline Steel & $\mathrm{C}$ & $\mathrm{S}$ & $\mathrm{P}$ & $\mathrm{Cu}$ & $\mathrm{Cr}$ & $\mathrm{Ni}$ & $\mathrm{Si}$ & $\mathrm{Mn}$ \\
\hline Low carbon bainitic steel & 0.054 & $<0.01$ & $<0.01$ & 0.4 & 0.4 & 0.51 & 0.26 & 0.58 \\
Corten-A steel & 0.08 & 0.023 & 0.07 & 0.41 & 0.6 & 0.3 & 0.5 & 0.4 \\
E550 steel & $<0.2$ & $<0.01$ & $<0.01$ & 0.44 & 0.4 & 0.65 & 0.26 & 1.38 \\
\hline
\end{tabular}


of corrosion products to $\mathrm{ZnO}$ was $7: 3$ [33]. The calibration analysis was executed by MDI Jade6. The diffraction intensity of (011) reflection of $\alpha-\mathrm{FeOOH},(110)$ reflection of $\beta$-FeOOH and (220) reflection of $\mathrm{Fe}_{3} \mathrm{O}_{4}$ was measured and compared with (100) reflection of $\mathrm{ZnO}$ powder.

The cross sections of rust layers were analyzed by scanning electron microscopy (SEM, ZEISS EVO18).

\section{$2.5 \mathrm{~N}_{2}$ Adsorption Test}

The specific surface areas of corrosion products on steel samples were measured by $\mathrm{N}_{2}$ adsorption method. $\mathrm{N}_{2}$ adsorption experiments were carried out at $78 \mathrm{~K}$ using AUTOSORB-6B equipment. Before the test, the samples were degassed for $2 \mathrm{~h}$ at $373 \mathrm{~K}$ in vacuum $\left(10^{-3}\right.$ Torr $)$. The cross-sectional area $\left(0.162 \mathrm{~nm}^{2}\right)$ of $\mathrm{N}_{2}$ molecules was used to determine the adsorption isotherm, from which the specific surface area of rust particles can be obtained.

\subsection{Ethanol Adsorption/Dehydration Method}

The adsorption/dehydration test of ethanol consists of the following steps: (1) weighing the rusted samples; (2) immersing the rusted samples in the anhydrous ethanol; (3) taking the rusted samples from the anhydrous ethanol and re-weighing them immediately; (4) repeating the above steps from (2) to (3) at regular intervals during the adsorption until the adsorption mass does not change with time and the adsorption process reaches saturation; (5) drying the samples with saturated adsorption of ethanol in a temperature-controlled oven at $313 \mathrm{~K}$; (6) weighing the samples at regular intervals during the dehydration until the dehydration mass does not change with time and the dehydration process is complete.

An analytical balance with an accuracy of $0.1 \mathrm{mg}$ was used in the test. Samples with adsorption in step (3) were inverted for 1 min before being weighed, to ensure the accuracy of the results. At least three samples were tested per group.

\section{Models}

\subsection{Basic Assumptions}

(1) All the water and air molecules adsorbed on the rust layers before the samples were subjected to adsorption/ dehydration test of ethanol will be dissolved into the ethanol during the adsorption.

(2) After the adsorption/dehydration test of ethanol, only are ethanol molecules adsorbed on the rust layers while there are no water or air molecules adsorbed on the rust layers even though the samples are exposed in the atmosphere.

(3) After the adsorption/dehydration test of ethanol, the rust layers are homogeneously and fully covered by the ethanol molecules. Meanwhile, the layer number of the adsorbed ethanol molecules must be an integer.

\subsection{Theoretical Derivation}

The total surface area (SA) of rust particles is given by Eq. (1):

$\mathrm{SA}=\frac{x}{n \rho h}$.

And the specific surface area (SSA) can be as follows:

$\mathrm{SSA}=\frac{x}{n \rho h M}$

$x=m_{\mathrm{R}}+\Delta m \quad(\Delta m>0)$.

where $n$ is the layer number of adsorbed molecules, $m_{\mathrm{R}}$ is the mass gain of sample from the adsorption/dehydration test, $\Delta m$ is the mass of water and air molecules adsorbed on the rust layers before adsorption/dehydration test (which has been replaced by ethanol after the adsorption/dehydration test), $x$ is the mass of adsorbed ethanol from the adsorption/ dehydration test (which is larger than $m_{\mathrm{R}}$ due to its containing of the part of ethanol replacing originally adsorbed water and air molecules), $M$ is the mass of the rust layer measured according to ISO8407-2009 [31] and GB/T16545-2015 [32] (the mass difference between the samples before and after the rust layers were removed), $h$ is the molecular size of adsorbed molecules [34, 35] and $\rho$ is the density of the ethanol [35].

However, there is a great difficulty on determining the values of $n$ and $x$. In the present investigation, a doubleadsorbate adsorption/dehydration method has been proposed to overcome the barrier. The method consists of subsequent adsorption/dehydration process of two mutually soluble adsorbates with similar molecular size, such as ethanol and acetone, for the same sample. Since the SSA of the sample is irrelative to adsorbate type, Eq. (4) can be obtained.

$$
\begin{gathered}
(\mathrm{SSA})_{1}=(\mathrm{SSA})_{2} \\
\Downarrow \\
\frac{n_{1}}{n_{2}}=\frac{x_{1} h_{2} \rho_{2}}{x_{2} h_{1} \rho_{1}}=\frac{x_{1} h_{2} \rho_{2}}{\left(x_{1}+m_{\mathrm{R} 2}-m_{\mathrm{R} 1}\right) h_{1} \rho_{1}}=\frac{1}{1+\frac{m_{\mathrm{R} 2}-m_{\mathrm{R} 1}}{x_{1}}} \frac{h_{2} \rho_{2}}{h_{1} \rho_{1}} \quad\left(x_{1}>m_{\mathrm{R} 1}\right) .
\end{gathered}
$$


It should be noted that since the $n$ value must be an integer, the $n_{1} / n_{2}$ value must be the simplest integer ratio. In this way, the values of $n$ and $x$ can be determined simultaneously. It is necessary to point out that, when the adsorption/dehydration process of ethanol and acetone is carried out subsequently, there is little influence between them, due to their mutual solution. For example, while the rust layers with adsorbed acetone molecules are subjected to the adsorption/dehydration test of ethanol, the adsorbed acetone molecules will dissolve in the ethanol at large extent.

The other important problem is the adsorption orientation of the molecules. According to the molecular configuration of ethanol and acetone, it can be assumed that adsorption occurs in the way as shown in Fig. 1. This is due to the fact that the functional groups of organic molecules are the determinants of their chemical properties. In this way, the $h$ value can be determined.

In the present investigation, the experimental results show that the $n$ value is 1 for ethanol while it is 4 for acetone. By the adsorption orientation depicted in Fig. 1, the phenomenon can be simply interpreted. When the rust layer is covered by one layer of ethanol molecules, the other ethanol molecules can bond with the molecules adsorbed to the rust layers only by an end of the chain-like molecule, which means a weak bond so that multi-layer adsorption is difficult to form. However, when an additional acetone molecule approaches the molecular layer of acetone, more van der Waals bonds can be formed, according to Fig. 1. Thus, multi-layer adsorption is easier to achieve in the situation.

Thus, the specific surface area (SSA) of rust particles using ethanol adsorption data can be modified as Eq. (5):

$\mathrm{SSA}=\frac{x}{\rho h M} \quad(n=1)$.

By means of the mass of the rust layer, the total pore volume per unit mass of rust layer, defined here as the porosity, could be determined by Eq. (6):

$V_{M}=\frac{V}{M}=\frac{m_{\mathrm{S}}}{\rho M}$

where $m_{\mathrm{S}}$ is the saturated adsorption mass, obtained from the adsorption process; $V$ is the total pore volume in the rust layer.

(a)

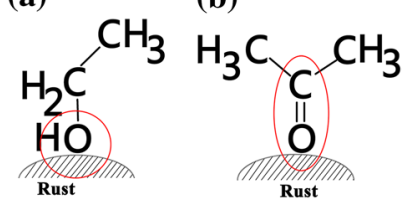

Fig. 1 Schematic diagram of molecule adsorption orientation: a ethanol $\mathbf{b}$ acetone
The porosity defined above can reveal the influence of larger pores and macro-defects in the rust layers, which is not reflected from $\mathrm{N}_{2}$ adsorption method.

The total surface area (SA) of rust particles obtained in Eq. (1) is also the total surface area of pores in the rust layers. Combining the saturated adsorption mass, the SSA of pores in the rust layers, i.e., $\mathrm{SSA}_{\mathrm{V}}$, can be obtained by Eq. (7):

$\mathrm{SSA}_{V}=\frac{\mathrm{SA}}{V}=\frac{x}{\rho h} \times \frac{\rho}{m_{\mathrm{S}}}=\frac{x}{h m_{\mathrm{S}}}$.

The $\mathrm{SSA}_{\mathrm{V}}$ can be used to reflect the mean size of pores.

Compared to $\mathrm{N}_{2}$ adsorption, there are several advantages in the ethanol adsorption/dehydration method. (1) The originally adsorbed water and air molecules are removed by dissolution in ethanol rather than by degassing and heating in vacuum, which makes almost no damage to the rust layers. (2) The method maintains the integrity of rust layers. (3) The method can characterize the compactness of inner rust layers.

\section{Results}

\subsection{Ethanol Adsorption/Dehydration Rates of Different Samples}

The ethanol adsorption/dehydration was applied to the rust layers on Corten-A, E550 and LCB steels corroded for 120 $\mathrm{d}$, and the results are shown in Fig. 2. Figure 2a, b shows the adsorption and dehydration results of different samples, while Fig. 2c and d reflects the corresponding adsorption and dehydration rates. All the samples exhibit obviously larger adsorption rates during the early stage, indicating that there are fast channels through which the ethanol molecules could be rapidly adsorbed. After $3 \mathrm{~h}$, the change of adsorption mass is little to all the samples, meaning that the larger pores have been filled with the anhydrous ethanol, while the following adsorption proceeds slowly by small pores. According to the figure, both the adsorption rates and dehydration rates exhibit the sequence: Corten-A > E550 > LCB samples.

According to the dehydration curves (Fig. 2b), in all the samples, the residual adsorption mass of anhydrous ethanol in Corten-A sample is always larger than E550 and LCB samples, indicating that there are more ethanol molecules adsorbed by the rust particles. The result seems to mean that the rust layers on Corten-A possess larger SSA and are more compact. However, the thickness of rust layers on different samples has not been taken into account in the results, which might produce an influence on the interpretation of the results. 

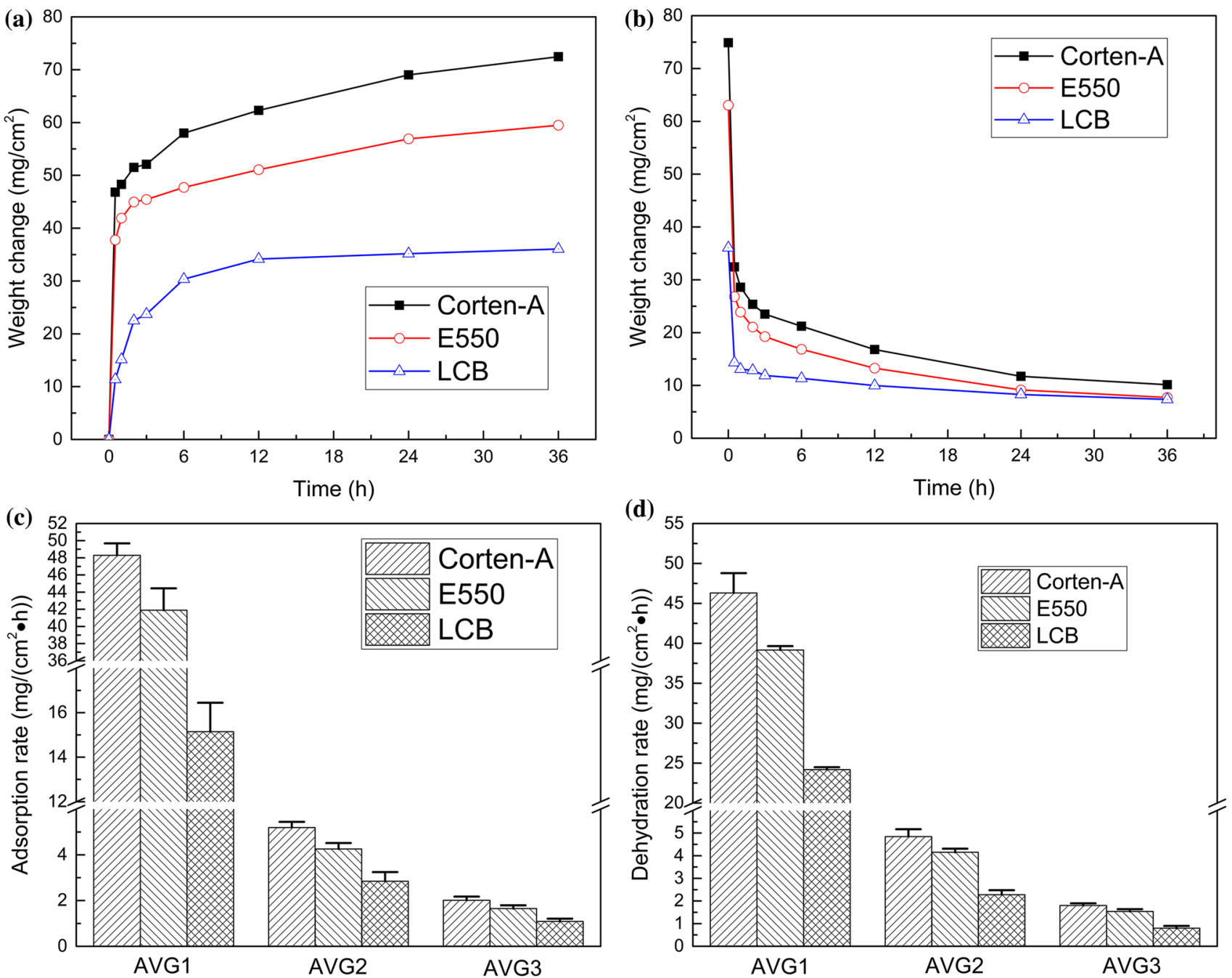

Fig. 2 Adsorption/dehydration results of ethanol for Corten-A, E550 and LCB samples: a adsorption process, b dehydration process, $\mathbf{c}$ adsorption rate $\mathbf{d}$ dehydration rate. (AVG1: average rate from 0 to $1 \mathrm{~h}$; AVG2: average rate from 0 to $12 \mathrm{~h}$; AVG3: average rate from 0 to $36 \mathrm{~h}$.)

Figure 3 shows the cross-sectional images of rust layers on Corten-A, E550 and LCB samples. As can be seen, the thickness of rust layers on Corten-A sample, about $500 \mu \mathrm{m}$, is larger than LCB. It was also found that there were many pores and cracks in the rust layers.
Figure $4 \mathrm{a}, \mathrm{b}$ shows the adsorption and dehydration curves per unit mass of rust for different samples, while Fig. $4 \mathrm{c}$ and $\mathrm{d}$ reflects the corresponding adsorption and dehydration rates. It can be found that adsorption/ dehydration rates (Fig. 4c, d) per unit mass of rust for LCB sample are always smaller than Corten-A and E550
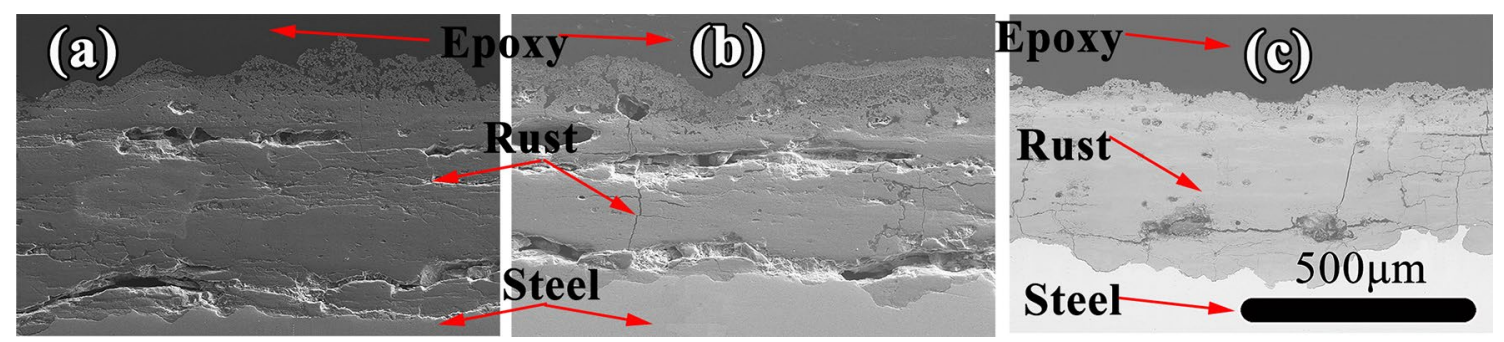

Fig. 3 Cross-sectional images of rust layers on all samples: a Corten-A, b E550 c LCB 

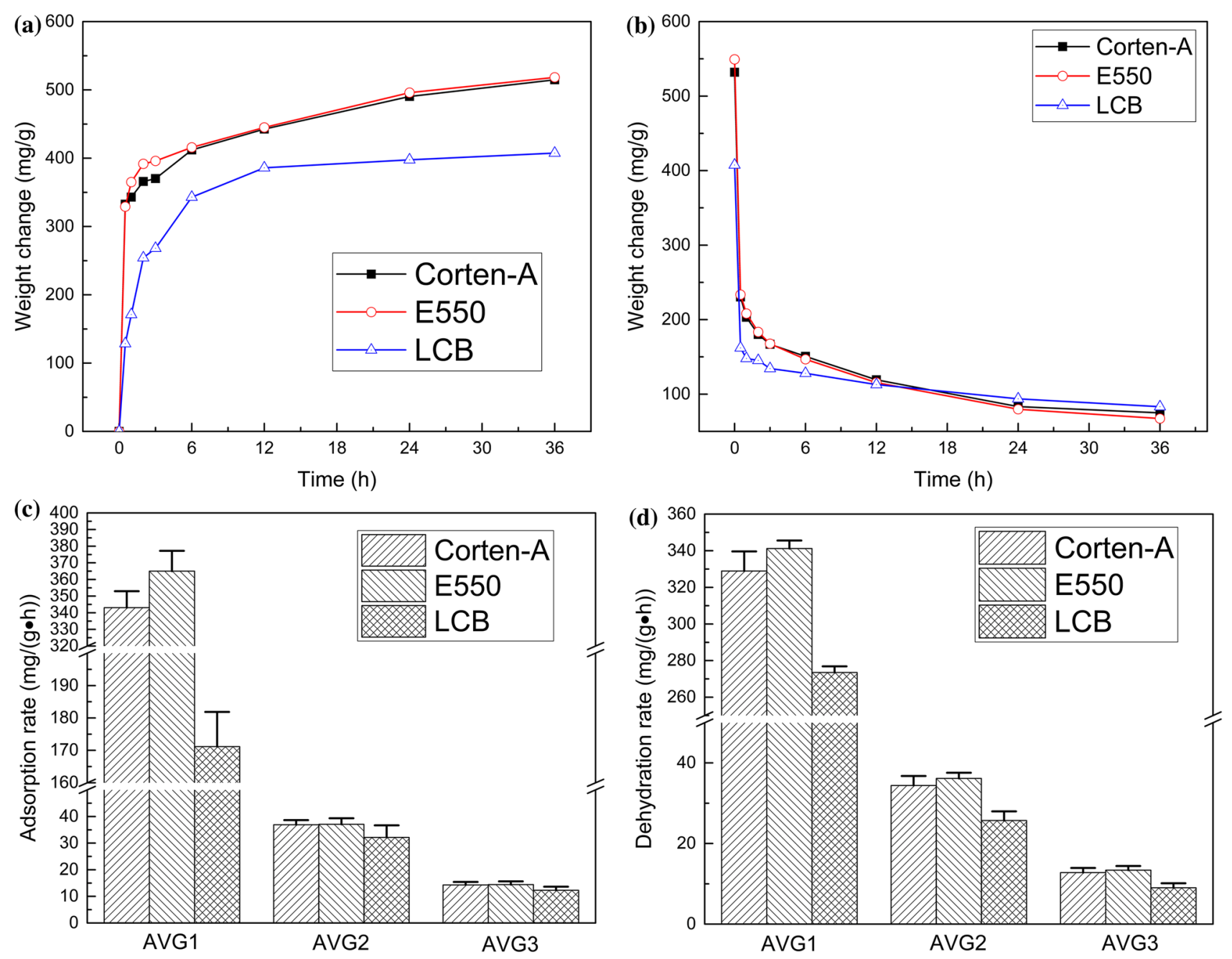

Fig. 4 Ethanol adsorption/dehydration curves and adsorption/dehydration rates per unit mass of rust for Corten-A, E550 and LCB samples: a adsorption process, $\mathbf{b}$ dehydration process, $\mathbf{c}$ adsorption rate $\mathbf{d}$ dehydration rate. (AVG1: average rate from 0 to $1 \mathrm{~h}$; AVG2: average rate from 0 to $12 \mathrm{~h}$; AVG3: average rate from 0 to $36 \mathrm{~h}$.)

samples. The results reflect that the total pore volumes per unit mass of rust for LCB sample are smaller than those for Corten-A and E550 samples.

On the other hand, the residual ethanol adsorption per unit mass of corrosion products reflects the surface area of corrosion products on the experimental steels. It can be found in Fig. 4b that the residual adsorption mass per unit mass of rust layers on LCB sample is larger than Corten-A and E550 samples, combining with the previous result, implying that the pore size in the rust layers on LCB sample is smaller, which will be quantitatively analyzed in the following part 4.3.

\subsection{Specific Surface Area from the Adsorption/ Dehydration Tests}

The SSA model above was applied to calculate the specific surface area of rust particles on Corten-A, E550 and LCB samples. The specific surface areas by Eq. (5) are shown in Table 2 and Fig. 5. In general, the larger is the SSA, the smaller is the size of rust particles, and the superior is the compactness of rust layers [22]. The specific surface areas of rust particles on all three samples follow the sequence: LCB $>$ E550 > Corten-A, contrary to the sequence of adsorption rates and dehydration rates shown in Fig. 2c, d. 
Table 2 Specific surface area results of rust layers on Corten-A, E550 and LCB samples by ethanol adsorption/ dehydration method

\begin{tabular}{llccccc}
\hline Sample & & $\begin{array}{l}m_{\mathrm{R}} \\
\left(\mathrm{mg} / \mathrm{cm}^{2}\right)\end{array}$ & $\begin{array}{l}x \\
\left(\mathrm{mg} / \mathrm{cm}^{2}\right)\end{array}$ & $n$ & $\begin{array}{l}M \\
\left(\mathrm{mg} / \mathrm{cm}^{2}\right)\end{array}$ & $\begin{array}{l}\text { SSA } \\
\left(\mathrm{m}^{2} / \mathrm{g}\right)\end{array}$ \\
\hline \multirow{2}{*}{ Corten-A } & Ethanol & 2.74 & 3.46 & 1 & 140.77 & 60.93 \\
& Acetone & 13.09 & 13.81 & 4 & & \\
\multirow{2}{*}{ E550 } & Ethanol & 2.51 & 3.54 & 1 & 114.77 & 76.57 \\
& Acetone & 13.12 & 14.15 & 4 & & \\
\multirow{2}{*}{ LCB } & Ethanol & 2.47 & 3.47 & 1 & 88.49 & 97.50 \\
& Acetone & 12.87 & 13.87 & 4 & & \\
\hline
\end{tabular}

$m_{\mathrm{R}}$ is mass gain of sample from the adsorption/dehydration test, $x$ is the mass of adsorbed ethanol from the adsorption/dehydration test, $h$ is the molecular size of adsorbed molecules $(0.51 \mathrm{~nm})$ [34, 35], $M$ is the mass of the rust layer, $\rho$ is the density of the ethanol $\left(0.789 \mathrm{~g} / \mathrm{cm}^{3}, 20^{\circ} \mathrm{C}\right)[34,35]$, and $n$ is the layer number of adsorbed molecules

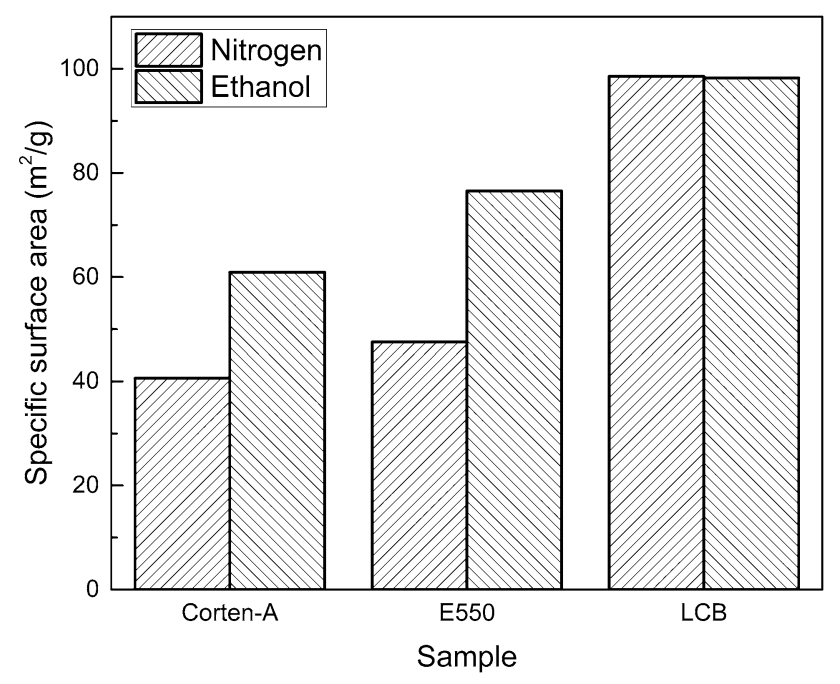

Fig. 5 Specific surface area results of rust layers on Corten-A, E550 and LCB samples by ethanol adsorption/dehydration method and $\mathrm{N}_{2}$ adsorption test

\subsection{Porosity by Ethanol Adsorption/Dehydration Method}

Table 3 shows the porosity of Corten-A, E550 and LCB samples by ethanol adsorption/dehydration method. According to the model, the saturated adsorption mass per unit mass of corrosion products ( $m_{\mathrm{SM}}$ in Table 3 ) on LCB sample is smaller than E550 and Corten-A. The pore volume per unit mass in the rust layers, i.e., $V_{\mathrm{M}}$ (defined as the porosity), was obtained according to Eq. (6). Considering E550 sample as an example, the $V_{\mathrm{M}}$ value is 0.66 , indicating that the rust layer is relatively loose. Porosity is an important parameter affecting the fluid transport performance in porous media, which directly reflects the compactness of rust layers.

Porosity can also provide some information about the corrosion process. For example, if the chemical and electrochemical reactions involved in the corrosion are not uniform, it will cause local stress concentration. In this way, defects such as cracks and voids would be introduced into the rust layer. Porosity of the rust layer defined in the paper will increase obviously, while the specific surface area produces little change.

As shown in Table 3, the $\mathrm{SSA}_{\mathrm{V}}$ (the SSA of pores in the rust layers) obtained according to Eq. (7) can be used to reflect the mean size of pores. It can be found that $\mathrm{SSA}_{\mathrm{V}}$ of LCB sample is much larger than those of E550 and CortenA, indicating that pores in the rust layers on LCB sample are smaller.

\subsection{Ethanol Adsorption/Dehydration Tests for Inner Rust Layer}

The ethanol adsorption/dehydration tests were applied to the inner rust layers [36] on weathering steels to demonstrate the applicability. The method of removing the outer rust layers is described in the literature [26, 27].
Table 3 Porosity of Corten-A, E550 and LCB samples by ethanol adsorption/dehydration method

\begin{tabular}{lllllll}
\hline Sample & $M\left(\mathrm{mg} / \mathrm{cm}^{2}\right)$ & $m_{\mathrm{S}}\left(\mathrm{mg} / \mathrm{cm}^{2}\right)$ & $m_{\mathrm{SM}}(\mathrm{mg} / \mathrm{mg})$ & $V\left(10^{-3} \mathrm{~cm}^{3} / \mathrm{cm}^{2}\right)$ & $V_{\mathrm{M}}\left(\mathrm{cm}^{3} / \mathrm{g}\right)$ & $\mathrm{SSA}_{\mathrm{V}}\left(10^{8} / \mathrm{m}\right)$ \\
\hline Corten-A & 140.77 & 72.46 & 0.51 & 91.84 & 0.65 & 1.41 \\
E550 & 114.77 & 59.48 & 0.52 & 75.39 & 0.66 & 1.87 \\
LCB & 88.49 & 36.05 & 0.41 & 45.69 & 0.52 & 3.05 \\
\hline
\end{tabular}

$M$ is the mass of the rust layer, $m_{\mathrm{S}}$ is the saturated adsorption mass, $m_{\mathrm{SM}}$ is the saturated adsorption mass per unit mass of rust $\left(=m_{\mathrm{S}} / M\right)$, $\mathrm{SSA}_{\mathrm{V}}$ is the SSA of the pores in the rust layers, $V$ is the total pore volume in the rust layers, and $V_{\mathrm{M}}$ is the pore volume per unit mass in the rust layers (defined as the porosity) 
Figure 6 shows the specific surface areas of rust layers on Corten-A and LCB samples by ethanol adsorption/dehydration method. It can be found that the SSA of inner rust layers is significantly larger than that of outer rust layers. According to previous study, the inner rust layer, from which the corrosion resistance of weathering steel mainly derives [37, 38], is mainly composed of nanoscale particles of corrosion products $[10,39,40]$.

Furthermore, it can be seen that the SSA of outer rust layers is close to that of complete rust layers. According to Fig. 6, the SSA of inner rust layers on LCB sample is also obviously greater than that of Corten-A sample, consistent to comparison between their complete rust layers.

\section{5 $\mathrm{N}_{2}$ Adsorption Test}

Table 4 and Fig. 5 show the specific surface areas of corrosion products in the rust layers on Corten-A, E550 and LCB samples by $\mathrm{N}_{2}$ adsorption method. The specific surface areas of corrosion products [22] on all three samples follow the sequence: LCB > E550 > Corten-A, consistent with the

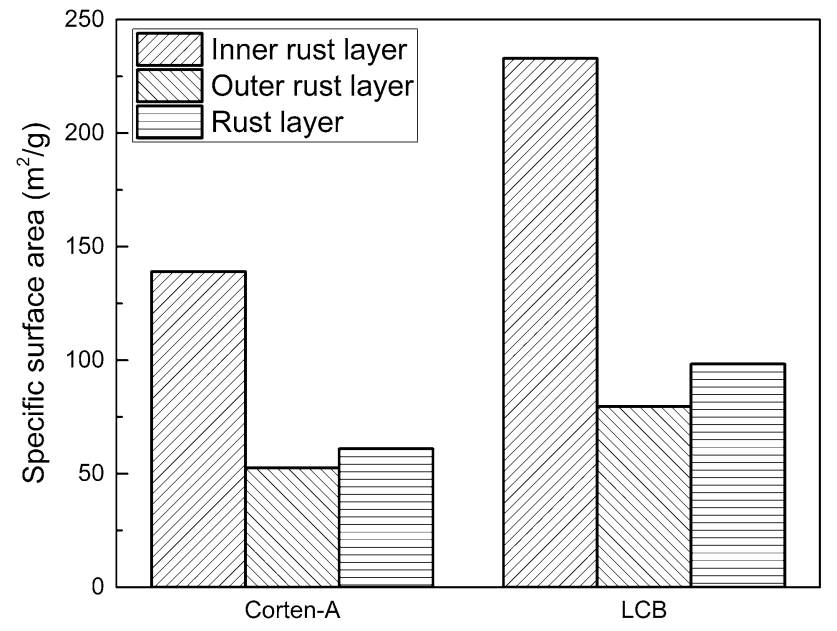

Fig. 6 Specific surface area results of inner and outer rust layers on Corten-A and LCB samples by ethanol adsorption/dehydration method sequence of specific surface area results by ethanol adsorption/dehydration method in Table 2 and Fig. 5. Meanwhile, almost the same SSA values of LCB sample are obtained by the two methods.

It can also be found that the specific surface areas of Corten-A and E550 samples by ethanol adsorption/dehydration are higher than those by $\mathrm{N}_{2}$ adsorption. This might be attributed to the defects and internal stress in the rust layers on Corten-A and E550 samples. These defects and internal stress will produce an influence on the adsorption of ethanol [27], while they are destroyed and released by $\mathrm{N}_{2}$ adsorption method.

It should be also noted that $\mathrm{N}_{2}$ adsorption test was carried out after the rust layers were deaerated vacuum to exclude the interference from moisture. In view of this, $\mathrm{N}_{2}$ adsorption tests were also tentatively carried out without vacuum deaeration [25]. The specific surface areas results (Table 4) are significantly smaller compared to normal treatment, which indicates that vacuum deaeration is a necessary pretreatment for $\mathrm{N}_{2}$ adsorption test.

Furthermore, it can be seen that the SSA of outer rust layers by ethanol adsorption/dehydration method (Fig. 6) is close to the specific surface areas results by $\mathrm{N}_{2}$ adsorption in Table 4 . The results by $\mathrm{N}_{2}$ adsorption mainly reflect the property of outer rust layers and cannot fully reflect the overall protective ability of complete rust layers [27]. The new method evaluates the compactness of rust layers rather than that of corrosion products removed from the metal surfaces, which is generally practiced in classic $\mathrm{N}_{2}$ adsorption method. And the ethanol adsorption/dehydration method considers the role of inner rust layers in determining the compactness of rust layers.

\subsection{Constituents of Rust Layers}

Figure $7 \mathrm{~b}$ shows the constituents of rust layers obtained from the quantitative analysis [33] of XRD spectra (Fig. 7a). It can be found that, the corrosion products [41] on weathering steels mainly consist of: $\alpha-\mathrm{FeOOH}, \beta-\mathrm{FeOOH}, \gamma-\mathrm{FeOOH}$, $\mathrm{Fe}_{3} \mathrm{O}_{4}$ and a high content of amorphous compounds [42-44].
Table 4 Specific surface area results of rust layers on Corten-A, E550 and LCB samples by $\mathrm{N}_{2}$ adsorption method

\begin{tabular}{lrccrr}
\hline Sample & Slope & Intercept & $\begin{array}{l}\text { Correlation } \\
\text { coefficient }\end{array}$ & C constant & SSA $\left(\mathrm{m}^{2} / \mathrm{g}\right)$ \\
\hline Corten-A & 85.243 & 0.475 & 0.999936 & 180.339 & 40.627 \\
Corten-A without VD & 389.946 & 14.00 & 0.999932 & 28.863 & 8.621 \\
E550 & 72.841 & 0.394 & 0.999969 & 185.621 & 47.552 \\
E550 without VD & 461.155 & 18.90 & 0.999943 & 25.401 & 7.254 \\
LCB & 35.109 & 0.231 & 0.999980 & 152.821 & 98.542 \\
LCB without VD & 213.335 & 6.821 & 0.999931 & 32.277 & 15.818 \\
\hline
\end{tabular}

$V D$ Vacuum deaeration 
(a)

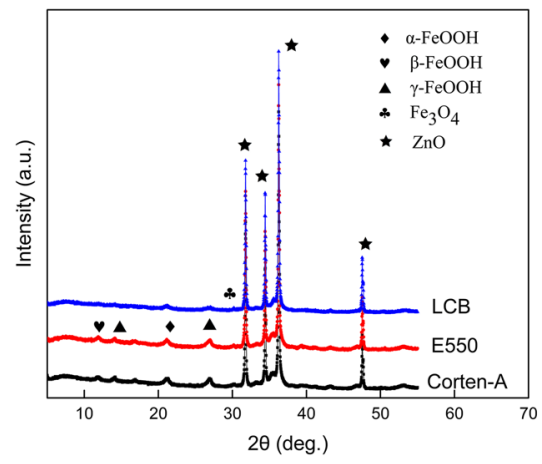

(b)

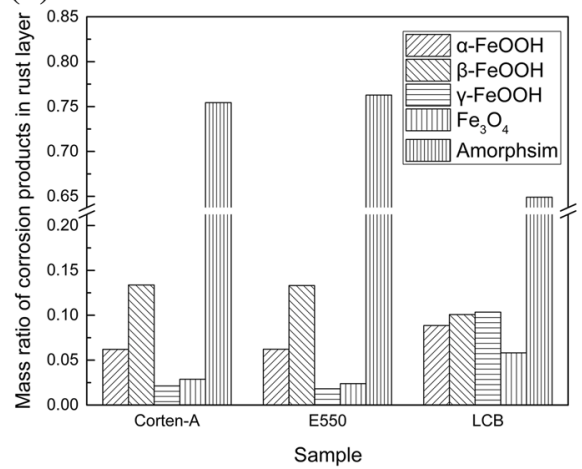

(c)

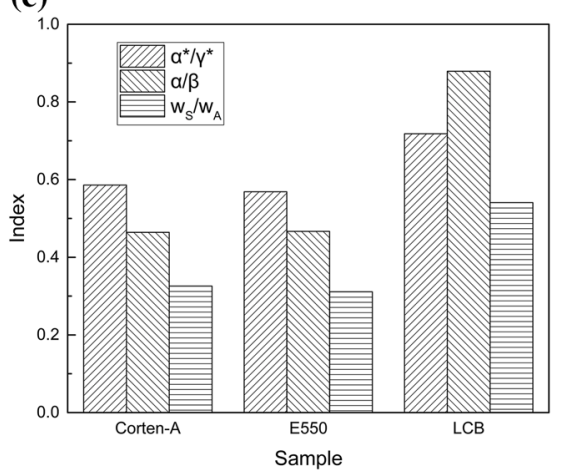

Fig. 7 a XRD results of Corten-A, E550 and LCB samples, b constituents of rust layers (mass ratio of different corrosion products, including goethite, magnetite, lepidocrocite, akaganeite and amorphism) $\mathbf{c}$ index of $\alpha^{*} / \gamma^{*}, \alpha / \beta$ and $w_{\mathrm{S}} / w_{\mathrm{A}}$ (where $w_{\mathrm{S}}$ is the mass $\%$ of goethite + magnetite + lepidocrocite + akaganeite, $w_{\mathrm{A}}$ is the mass $\%$ of amorphism)

The $\alpha^{*} / \gamma^{*}$ ratio can be used as an index to evaluate the protective ability of rust layers $[1,33]$, in the same way as the $\alpha / \gamma$ ratio determined by the conventional XRD technique. It can be seen from Fig. 7c that the $\alpha^{*} / \gamma^{*}$ and $\alpha / \beta$ ratios of LCB sample, determined by XRD, are larger than those of Corten-A and E550 samples. The mass ratio of goethite + akaganeite + lepidocrocite + magnetite to amorphous compounds on LCB sample, the $w_{\mathrm{S}} / w_{\mathrm{A}}$ ratio, determined by $\mathrm{XRD}$, is larger than Corten-A and E550 samples. The results show that relatively higher densification and stabilization of rust layers [2,3] are achieved simultaneously for LCB samples.

\subsection{Electrochemical Properties of Rust Layers}

Electrochemical impedance spectroscopy (EIS, Fig. 8a) data were fitted by ZSimpWin software [45, 46], and EIS equivalent electrical circuit model is shown in Fig. 8b. The rust resistance $\left(R_{\mathrm{r}}\right)$ reflects the ability of rust layers to resist the diffusion of corrosive ions into the rust layers $[7,8]$ and therefore can be used as a major index for evaluating the protective ability of rust layers $[9,10]$. Figure $8 d$ shows the fitted values of $R_{\mathrm{r}}$ for the rusted samples. It should be noted that, although the $\operatorname{Rr}$ value of E550 sample $(\sim 120 \Omega)$ is higher than Corten-A $(\sim 115 \Omega)$ and LCB $(\sim 112 \Omega)$, the difference in rust resistance between the three groups of samples is not particularly obvious, indicating that the ability to prevent the charge exchange in electrochemical reaction is almost the same, possibly due to the influence of the thickness of rust layers [29]. As can be seen in Fig. 3, the rust layers on Corten-A and E550 samples are obviously thicker than those on $\mathrm{LCB}$, which might result in an increase to the rust resistance despite their lower compactness.

The polarization curve (Fig. 8c) measurements were carried out, and the corresponding parameter values (Fig. 8d) of rust layers were obtained [27]. It can be seen that the free corrosion potential of Corten-A sample is approximately the same as E550, but the corrosion current density of E550 sample is smaller than Corten-A. It demonstrates that the protective ability of rust layers on E550 sample is better than Corten-A. And the free corrosion potential of LCB sample is higher than Corten-A and E550, and the corrosion current density of LCB sample is smaller than Corten-A and E550, indicating that the protective ability of rust layers is superior.

In summary, the results of ethanol adsorption/dehydration are consistent with the results of electrochemical tests, $\mathrm{N}_{2}$ adsorption and XRD analysis. These results suggest that the ethanol adsorption/dehydration method is applicable to the rust layers on weathering steels in different corrosion conditions.

\section{Discussion}

The pore size is critical to the compactness of rust layers, mainly because it governs the diffusion of molecules and ions $\left(\mathrm{O}_{2}, \mathrm{H}_{2} \mathrm{O}\right.$ and $\left.\mathrm{Cl}^{-}\right)$in the rust layers [20]. The smaller is the size of the rust particles, and the superior is the compactness of the rust layers [22]. The protective ability of rust layers on weathering steels is mainly reflected in slowing down further corrosion, thereby reducing the corrosion rate, rather than completely preventing it.

According to the classification of International Union of Pure and Applied Chemistry, pores sizes can be divided into three ranges, i.e., diameters less than $2 \mathrm{~nm}$, from $2 \mathrm{~nm}$ to $50 \mathrm{~nm}$ and larger than $50 \mathrm{~nm}$, which are called micropores, mesopores and macropores, respectively. The three adsorption methods carried out with $\mathrm{N}_{2}$ [14], water [26] and ethanol molecules are identical in principle and can be used to analyze the pores in the rust layers. The three methods can reveal pores larger than their molecular diameter or structural size. However, larger size of ethanol molecules 

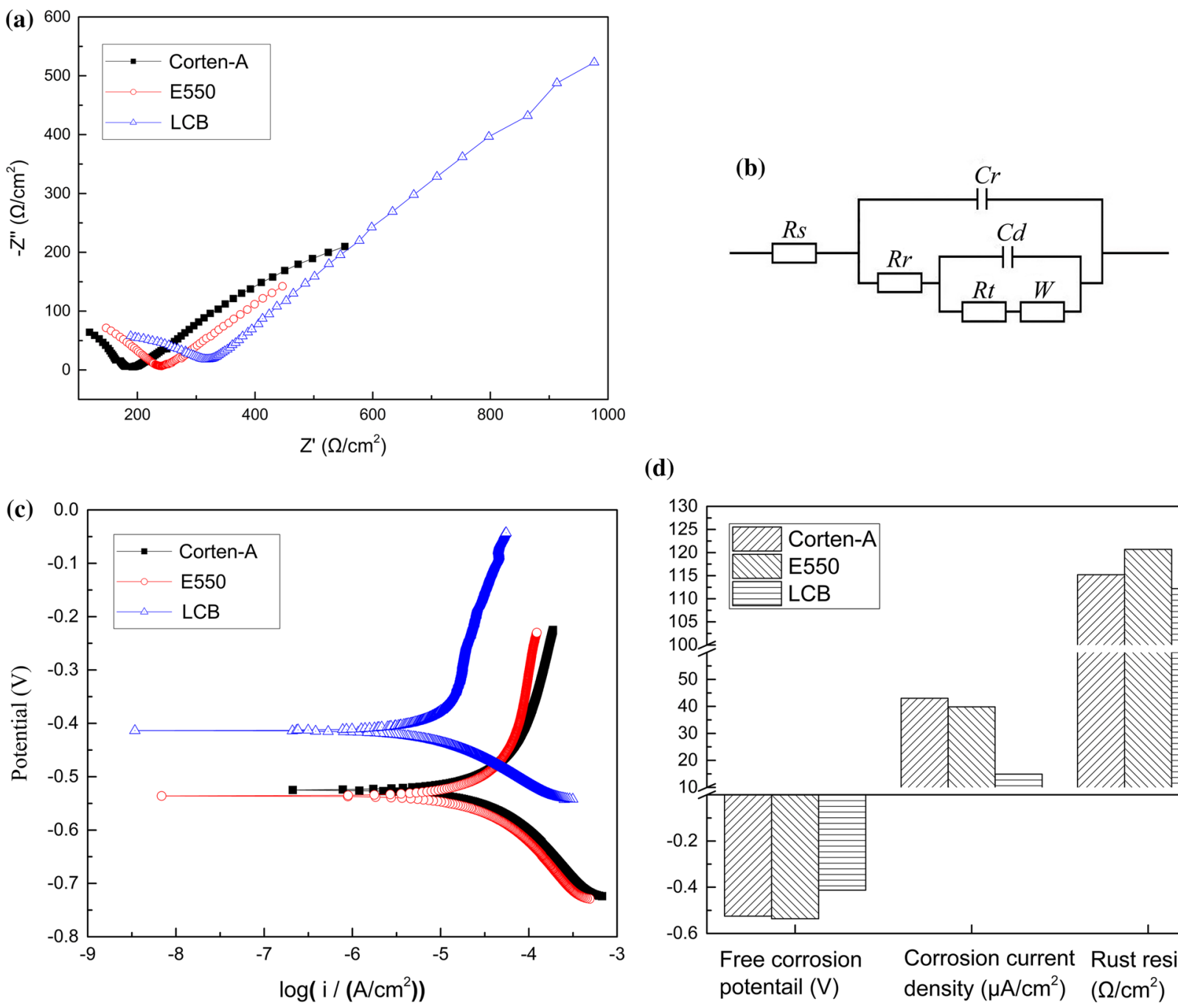

(d)

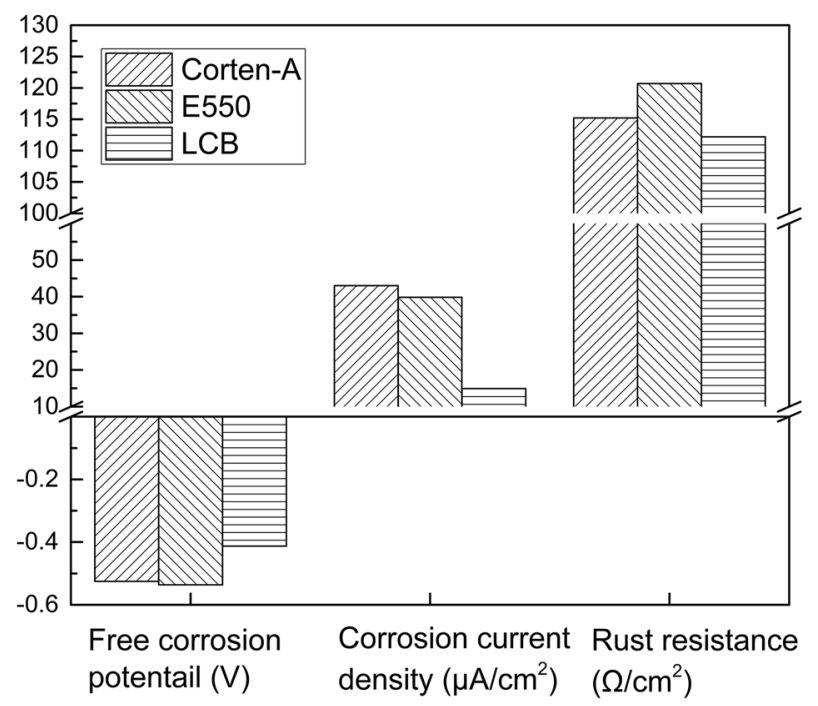

Fig. 8 Electrochemical results of Corten-A, E550 and LCB samples: a electrochemical impedance spectroscopy (EIS), b equivalent electrical circuit model for the EIS data $\left(R_{\mathrm{S}}\right.$ is the resistance of the solution, $R_{\mathrm{r}}$ is the resistance of the rust layer, $C_{\mathrm{r}}$ is the capacitance of the rust layer, $C_{\mathrm{d}}$ is the capacitance of the double layers, $R_{\mathrm{t}}$ is the charge transfer resistance, and $W$ is the Warburg impedance), $\mathbf{c}$ polarization curves $(i$, corrosion current density) d evolution of free corrosion potential, corrosion current density and rust resistance of rusted samples

compared to $\mathrm{N}_{2}$ and water molecules means lower sensibility to pores with small sizes.

In terms of CRC Handbook of Chemistry and Physics [35], the molecular diameter or structural size of water $(0.32 \mathrm{~nm})$ and ethanol $(0.51 \mathrm{~nm})$ can be obtained. In $\mathrm{N}_{2}$ adsorption method, the cross-sectional area $\left(0.162 \mathrm{~nm}^{2}\right)$ of $\mathrm{N}_{2}$ molecules was used to determine the adsorption isotherm $[22,23,25]$.

In the actual corrosion process, the manner in which oxygen is dissolved in water is mainly divided into gap filling and hydration, and is dominated by hydration [47], i.e., in the form of monohydrate $\left(\mathrm{O}_{2} \cdot \mathrm{H}_{2} \mathrm{O}\right)$ and dihydrate $\left(\mathrm{O}_{2} \cdot 2 \mathrm{H}_{2} \mathrm{O}\right)$. Further, both hydrogen ions and chloride ions exist mainly in the state of hydrated ions. Thus, real sizes of corrosive ions or molecules approximate the size of the ethanol molecules. On the other hand, this implies that pores in the rust layers should possess sizes comparative or larger than those of ethanol molecules in general. Thus, adsorption/ dehydration results of ethanol can reflect the compactness of rust layers in spite of larger size of ethanol molecules.

\section{Conclusions}

The method proposed in the present study includes adsorption and dehydration process of anhydrous ethanol for the rust layers on weathering steels. Through the measurement of adsorption rates and dehydration rates, the protective ability of rust layers can be qualitatively reflected. A quantitative model involving the specific surface area and the porosity 
of corrosion products in the rust layers has been proposed. The results from the proposed method are in good agreement with the results of electrochemical tests, $\mathrm{N}_{2}$ adsorption and XRD analysis. The method evaluates the compactness of rust layers rather than that of corrosion products removed from the metal surfaces, which is generally practiced in classic $\mathrm{N}_{2}$ adsorption method. Furthermore, the method can reflect the compactness of inner rust layers, to which $\mathrm{N}_{2}$ adsorption is unavailable. The method provides a new approach for the study of rust layers.

Acknowledgements This work is financially supported by the National Natural Science Foundation of China (No. 51571026).

\section{References}

[1] S. Hara, T. Kamimura, H. Miyuki, M. Yamashita, Corros. Sci. 49, $1131(2007)$

[2] M. Morcillo, I. Díaz, B. Chico, H. Cano, D. de la Fuente, Corros. Sci. 83, 6 (2014)

[3] M. Morcillo, B. Chico, I. Díaz, H. Cano, D. de la Fuente, Corros. Sci. 77, 6 (2013)

[4] S. Wang, S. Yang, K. Gao, X. He, Trans. Mater. Heat Treat. 29, $170(2008)$

[5] X. Yang, W. Zheng, Corros. Prot. 23, 97 (2002)

[6] Q. Zhang, J. Chen, J. Mater. Sci. Eng. 19, 12 (2001)

[7] U.R. Evans, C.A.J. Taylor, Corros. Sci. 12, 227 (1972)

[8] J.H. Wang, F.I. Wei, Y.S. Chang, H.C. Shih, Mater. Chem. Phys. 47, 1 (1997)

[9] L. Hao, S. Zhang, J. Dong, W. Ke, Corros. Sci. 59, 270 (2012)

[10] K. Asami, M. Kikuchi, Corros. Sci. 45, 2671 (2003)

[11] M. Yamashita, T. Misawa, Corrosion `98 (CA (United States), San Diego, 1998), p. 95

[12] P. Dillmann, F. Mazaudier, S. Hoerle, Corros. Sci. 46, 1401 (2004)

[13] J. Monnier, P. Dillmann, L. Legrand, I. Guillot, Corros. Eng. Sci. Technol. 45, 375 (2010)

[14] K. Sin, Colloids Surf. A 187, 3 (2001)

[15] International Organization for Standardization. ISO9277-2010 Determination of the specific surface area of solids by gas adsorption-BET method (2010)

[16] General Administration of Quality Supervision, Inspection and Quarantine of the People's Republic of China, Standardization Administration of the People's Republic of China. GB/T 195872004 Determination of the specific surface area of solids by gas adsorption using the BET method. Beijing: Standards Press of China (2004)

[17] N. Masuko, Y. Hisamatsu, Corros. Eng. Digest. 17, 539 (1968)

[18] T. Suzuki, H. Saito, K. Yoshioka, Y. Kitamura, Corros. Eng. Digest. 19, 133 (1970)

[19] M. Yamashita, K. Asami, T. Ishikawa, T. Ohtsuka, H. Tamura, T. Misawa, Zairyo-to-Kankyo 50, 521 (2001)

[20] T. Ishikawa, M. Kumagai, A. Yasukawa, K. Kandori, Corrosion 57, $346(2001)$
[21] T. Ishikawa, Zairyo-to-Kankyo. 54, 361 (2005)

[22] T. Ishikawa, T. Yoshida, K. Kandori, T. Nakayama, S. Hara, Corros. Sci. 49, 1468 (2007)

[23] T. Ishikawa, R. Tanaka, M. Minamigawa, K. Kandori, H. Tanaka, T. Nakayama, Mater. Corros. 66, 1460 (2015)

[24] T. Ishikawa, A. Maeda, K. Kandori, A. Tahara, Corrosion 62, 559 (2006)

[25] L. Tan, T. Liang, Y. Xiang, Q. Chen, Y. Ding, Mater. Res. Appl. 8, 137 (2014)

[26] X. Zhang, S. Yang, W. Zhang, H. Guo, X. He, Corros. Sci. 82, 165 (2014)

[27] X. Zhang, Dissertation, University of Science and Technology Beijing (2014)

[28] M. Zhang, S. Yang, W. Liu, X. He, C. Shang, X. Wang, H. Guo, W. Zhang, J. Guo, Z. Yin, Chin Patent 200910080987, 1 (2009)

[29] J. Han, H. Yan, Y. Huang, L. Zhou, S. Yang, Acta Metall. Sin. 53, 163 (2017)

[30] J. Dong, S. Zhang, H. Wang, W. Han, C. Liu, J. Wuhan Univ. Sci. Technol. Nat. Sci. Ed. 31, 127 (2008)

[31] International Organization for Standardization. ISO8407-2009 Corrosion of metals and alloys-Removal of corrosion products from corrosion test specimens (2009)

[32] General Administration of Quality Supervision, Inspection and Quarantine of the People's Republic of China, Standardization Administration of the People's Republic of China. GB/T 165452015 Corrosion of metals and alloys-Removal of corrosion products from corrosion test specimens. Beijing: Standards Press of China (2015)

[33] T. Kamimura, S. Hara, H. Miyuki, M. Yamashita, H. Uchida, Corros. Sci. 48, 2799 (2006)

[34] X. Fu, W. Shen, T. Yao, W. Hou, Physical Chemistry, 5th edn. (Higher Education Press, Beijing, 2005)

[35] W. N. Haynes, D. R. Lide, T. J. Bruno, CRC Handbook of Chemistry and Physics, 97th edn. (CRC Press, 2016-2017)

[36] M. Yamashita, H. Miyuki, Y. Matsuda, H. Nagano, T. Misawa, Corros. Sci. 36, 283 (1994)

[37] G. Liu, J. Dong, E. Han, W. Ke, Corros. Sci. Prot. Technol. 18, 268 (2006)

[38] L. Liu, H. Qi, Y. Lu, X. Li, Corros. Sci. Prot. Technol. 15, 86 (2003)

[39] R. Balasubramaniam, Corros. Sci. 42, 2103 (2000)

[40] T. Ishikawa, K. Takeuchi, K. Kandori, T. Nakayama, Colloids Surf. A 266, 155 (2005)

[41] D.C. Cook, Corros. Sci. 47, 2550 (2005)

[42] I. Martínez-Arkarazo, M. Angulo, L. Bartolomé, N. Etxebarria, M.A. Olazabal, J.M. Madariaga, Anal. Chim. Acta 584, 350 (2007)

[43] Z. Wang, J. Liu, L. Wu, R. Han, Y. Sun, Corros. Sci. 67, 1 (2013)

[44] J.A. Mejía Gómez, J. Antonissen, C.A. Palacio, E. De Grave, Corros. Sci. 59, 198 (2012)

[45] M. Stratmann, H. Streckel, K.T. Kim, S. Crockett, Corros. Sci. 30, 715 (1990)

[46] X. Chen, J. Dong, E. Han, W. Ke, Mater. Lett. 61, 4050 (2007)

[47] J. Han, J. Xi' an Univ. Nat. Sci. Ed. 20, 87 (2017) 